\title{
Necrosis related HIF-1a expression predicts prognosis in patients with endometrioid endometrial carcinoma
}

\author{
Laura MS Seeber ${ }^{\dagger 1}$, Nicole Horrée ${ }^{+1}$, Petra van der Groep², Elsken van der Wall33, René HM Verheijen ${ }^{1}$ and Paul J van \\ Diest*2
}

\begin{abstract}
Background: Hypoxia inducible factor 1a (HIF-1a) plays an essential role in the adaptive response of cells to hypoxia and is associated with aggressive tumour behaviour. We have shown p27kip 1 , which is generally reduced in endometrial cancer, to be re-expressed in hypoxic regions. This possibly contributes to survival of cancer cells. The aim of this study was to evaluate the prognostic value of HIF-1a and p27kip expression in patients with endometrioid endometrial cancer.

Methods: Expression levels of HIF-1a, CAIX, Glut-1, and p27kip1 were analyzed by immunohistochemistry. Percentage of positive cells, staining pattern (perinecrotic, diffuse, or mixed) and presence of necrosis were noted.

Results: Necrosis was correlated with shortened disease free survival (DFS) $(p=0.008)$ and overall survival (OS) ( $p=$ 0.045). For DFS, perinecrotic HIF-1 a expression was also prognostic $(p=0.044)$. Moreover, high $p 27$ kip 1 expression was an additional prognostic factor for these patients with perinecrotic HIF-1 a expression. In multivariate Cox regression, perinecrotic HIF-expression emerged as an independent prognostic factor. Perinecrotic HIF-1 a expression was significantly associated with CAIX and Glut-1 expression, pointing towards functional HIF-1.
\end{abstract}

Conclusions: In patients with endometrioid endometrial cancer, necrosis and necrosis-related expression of HIF-1a are important prognostic factors. More aggressive adjuvant treatment might be necessary to improve the outcome of patients with these characteristics.

\section{Background}

Endometrial cancer is the most common malignant tumour of the female genital tract. The American Cancer Society estimated that 42160 women have been diagnosed with, and 7780 women have died of cancer of the female genital tract in 2009 in the US[1]. In the endometrium different subtypes of cancer can develop. Endometrioid endometrial carcinoma (EEC), or Type 1 cancers, are oestrogen dependent, often develop in a background of atypical complex hyperplasia and account for over $75 \%$ of cases. EEC patients generally have a good prognosis, with low mortality for stage 1 disease (5-year survival around 87\%)[2]. However, survival drops in

*Correspondence: p.j.vandiest@umcutrecht.nl

2 Department of Pathology, University Medical Centre Utrecht, Utrecht, The Netherlands

+ Contributed equally

Full list of author information is available at the end of the article higher stage of disease. Additional prognostic factors could help to decide the need for adjuvant treatment and to identify new treatment strategies.

Solid tumours outgrow their own vasculature beyond the size of several $\mathrm{mm}^{3}$, resulting in hypoxia. Regions of necrosis are believed to demarcate regions of severe, chronic hypoxia[3]. Hypoxia is an important issue in carcinogenesis because it renders a more aggressive phenotype with increased invasiveness and proliferation, formation of metastases and poorer survival[4-8]. Besides, hypoxic malignant cells are more resistant to radiotherapy and chemotherapy[9-11]. In reaction to hypoxia, cells will alter their metabolism and activate certain survival genes. Hypoxia inducible factor 1 (HIF-1) plays an essential role in the adaptive cellular response to hypoxia[12,13]. HIF-1 is a transcription factor composed of the subunits HIF- $1 \alpha$ and HIF- $1 \beta$, which are basic helix-

( 2010 Seeber et al; licensee BioMed Central Ltd. This is an Open Access article distributed under the terms of the Creative Commons :HW 1 ed Central Attribution License (http://creativecommons.org/licenses/by/2.0), which permits unrestricted use, distribution, and reproduction in any medium, provided the original work is properly cited. 
loop-helix DNA binding proteins. HIF-1 $\beta$ is constitutively expressed at the protein level. The activity of HIF-1 is predominantly regulated at the post-translational level by regulating HIF-1 $\alpha$ protein stability. Under normoxia, HIF- $1 \alpha$ is hydroxylated by prolyl hydroxylases in the oxygen dependent degradation domain. Hydroxylated HIF$1 \alpha$ is recognized by the Von Hippel Lindau protein, ubiquitinated, and destined for degradation by the proteasome. This process is inhibited during hypoxia[14], where stabilized HIF- $1 \alpha$ heterodimerizes with HIF- $1 \beta$ to transactivate target genes after nuclear translocation by binding to the consensus Hypoxia Responsive Element (HRE) 5'-RCGTG-3' in promoters and enhancers[15]. Among these are growth factors, glucose transporters, glycolytic enzymes, and genes involved in gluconeogenesis, highenergy phosphate metabolism, erythropoiesis, haem metabolism, iron transport, vasomotor regulation and nitric oxide synthesis[13,15-17]. Protein products of these downstream genes help the cell to survive the hypoxic stress by increasing oxygen delivery (angiogenesis) and by switching to anaerobic glycolysis.

Previous breast cancer studies[6,7] showed that in hypoxic conditions, HIF- $1 \alpha$ expression is seen perinecrotically, with induction of its target genes carbonic anhydrase 9 (CAIX), that plays a role in $\mathrm{pH}$ regulation[18] and Glut-1, a transmembrane glucose transporter $[19,20]$. In normoxic conditions, HIF- $1 \alpha$ expression can also be induced by other mechanisms, but was to a much lesser extent associated with downstream activation. CAIX and Glut-1 thereby serve to identify functional HIF-1 $\alpha[7]$. In breast cancer, we showed that patients with a diffuse (non-hypoxia associated) HIF-1 $\alpha$ staining pattern had a relatively better prognosis[7]. Elevated levels of CAIX are predictive of hypoxia in various types of cancer and are related to poor prognosis[21,22]. The prognostic value of CAIX and Glut- 1 has not been studied in endometrial cancer. We previously suggested that HIF- $1 \alpha$ plays an important role in endometrial carcinogenesis[23]. In postmenopausal woman, HIF-1 $\alpha$ was increasingly overexpressed from inactive endometrium through hyperplasia to endometrioid carcinoma, paralleled by activation of its downstream genes. HIF-1 $\alpha$ overexpression has further been shown to be correlated with a poorer survival in cancers of the brain[24], cervix[25] and ovary[26]. As HIF- $1 \alpha$ is related to poor clinical outcome in some tumours, HIF-1 $\alpha$ expression could be used to identify patients who are at risk of developing recurrent disease and who may benefit from adjuvant therapy. Moreover, targeting HIF- $1 \alpha$ could be an attractive therapeutic strategy with the potential for disrupting multiple pathways crucial for tumour growth. In endometrial cancer, there are some conflicting data concerning the prognostic relevance of HIF-1 $\alpha$, probably due to varying methodology and patient groups[27-30]. Whether the different HIF-1 $\alpha$ expression patterns have different prognostic implications in endometrial cancer is yet unknown.

In accordance with the need to decrease energy usage under low oxygen conditions, hypoxia induces cell-cycle arrest[31]. Cell-cycle arrest is regulated by complex interactions between cyclins, cyclin-dependent kinases (CDKs), and cyclin-dependent kinase inhibitors (CKIs)[32]. p27kip1 is a CKI that regulates progression from $\mathrm{G}_{1}$ to $\mathrm{S}$ phase by inhibiting a variety of cyclin-CDK complexes. It has been shown that $\mathrm{p} 27^{\mathrm{kip} 1}$ expression is strongly reduced in endometrial cancer[33,34]. In a recent study on cell cycle regulation during endometrial carcinogenesis[23], p27kip1 protein was re-expressed in necrotic (i.e. hypoxic) areas of endometrial carcinomas. We showed that $\mathrm{p}^{2} 7^{\mathrm{kip} 1}$ re-expression by hypoxia was HIF- $1 \alpha$-dependent and led to cell cycle arrest. This possibly contributes to survival of cancer cells in hypoxic parts of the tumour[35].

Several studies demonstrated that loss of the p27kip1 protein, as assessed by immunohistochemistry, is a negative prognostic marker in malignancies[36,37]. However, the prognostic importance of HIF- $1 \alpha$ induced re-expression of p27kip1 is not known. Loss of p27kip1 expression in endometrial carcinoma did not seem to correlate with worse prognosis in previous studies[38,39].

Understanding the mechanisms of carcinogenesis and progression of endometrial cancer is important as these insights might lead to improved diagnostic tools for the pathologist, improved prediction of prognosis and response to therapy, and eventually better biology-based disease management in the individual patient. The aim of this study was therefore to (1) re-evaluate the prognostic value of HIF-1 $\alpha$ with emphasis on expression patterns and investigate the additional effect of $\mathrm{p} 27^{\mathrm{kip} 1}$ expression on predicting survival in EEC and (2) to determine relationships with the other clinicopathologic markers in the endometrioid type of endometrial cancer.

\section{Methods}

\section{Patients and Tissues}

The study group, diagnosed between 1992 and 2005 at the University Medical Centre Utrecht, The Netherlands, was composed as follows: a search in our tumour bank for patients with endometrioid endometrial cancer yielded 108 patients with paraffin embedded tumour tissue available. Patients with only endometrial sampling material available were not included in our study. Furthermore, patients were excluded if they had a second primary tumour of the cervix or ovary $(n=3)$, or a history of cervical carcinoma $(n=7)$. None of the patients received preoperative radio- or chemotherapy. Patient chart review was performed retrospectively; adequate followup data were lacking for 5 patients, leaving 93 patients. Table 1 gives an overview of the patient demographics 
Table 1: Patient demographics and main pathological features of the group of endometrioid endometrial cancer patients $(n=93)$.

\begin{tabular}{|c|c|c|c|}
\hline Variable & Grouping & $\mathbf{N}$ & (\%) \\
\hline \multirow[t]{3}{*}{ Age } & Mean & 62.51 & \\
\hline & Minimum & 31 & \\
\hline & Maximum & 88 & \\
\hline \multirow[t]{4}{*}{ Stage } & 1 & 54 & (58) \\
\hline & $\|$ & 21 & $(23)$ \\
\hline & III & 13 & (14) \\
\hline & IV & 5 & (5) \\
\hline \multirow[t]{3}{*}{ Grade } & 1 & 28 & (30) \\
\hline & 2 & 47 & (51) \\
\hline & 3 & 18 & (19) \\
\hline \multirow[t]{3}{*}{ Depth of myometrial invasion } & 0 & 3 & (3) \\
\hline & $<50 \%$ & 50 & (54) \\
\hline & $>50 \%$ & 40 & (43) \\
\hline \multirow[t]{2}{*}{ Necrosis } & Present & 70 & (75) \\
\hline & Absent & 23 & (25) \\
\hline \multirow[t]{4}{*}{ HIF-1a expression } & $<1 \%$ & 0 & (0) \\
\hline & $\geq 1 \%$ & 93 & $(100)$ \\
\hline & $<35 \%$ & 74 & $(80)$ \\
\hline & $\geq 35 \%$ & 19 & $(20)$ \\
\hline \multirow[t]{3}{*}{ HIF-1a expression pattern§ } & Purely Perinecrotic & 20 & $(21)$ \\
\hline & Purely Diffuse & 39 & $(42)$ \\
\hline & Mixed & 34 & (37) \\
\hline \multirow[t]{2}{*}{ CAIX } & Positive & 71 & (76) \\
\hline & Negative & 22 & (24) \\
\hline \multirow[t]{2}{*}{ Glut-1 } & Positive & 76 & $(81)$ \\
\hline & Negative & 17 & (19) \\
\hline \multirow[t]{2}{*}{ p27kip1 } & Positive & 86 & (93) \\
\hline & Negative & 7 & (7) \\
\hline \multirow{3}{*}{$\begin{array}{l}\text { Follow up time (for surviving } \\
\text { patients, in months) }\end{array}$} & Minimum & 13 & \\
\hline & Maximum & 182 & \\
\hline & Mean & 66 & \\
\hline
\end{tabular}

Table 1: Patient demographics and main pathological features of the group of endometrioid endometrial cancer patients $(n=93)$. (Continued)

\begin{tabular}{llcc}
\hline Recurrence/Metastasis & Yes & 18 & (19) \\
& No & 72 & (78) \\
& Missing & 3 & (3) \\
\hline Survival & Alive & 71 & $(76)$ \\
& $\begin{array}{l}\text { Death of } \\
\text { endometrial cancer }\end{array}$ & 11 & $(12)$ \\
& $\begin{array}{l}\text { Death of } \\
\text { intercurrent } \\
\text { disease } \\
\text { Cause of death } \\
\text { unknown }\end{array}$ & 10 & $(11)$ \\
& & & \\
& & &
\end{tabular}

§ Perinecrotic HIF present $=$ mixed and purely perinecrotic HIF pattern grouped.

and main pathological features. Haematoxylin and eosinstained sections were revised and histologically graded. The tumour stage was defined by the International Federation of Gynaecologists and Obstetricians (FIGO) system. Anonymous use of redundant tissue for research purposes is part of the standard treatment agreement with patients in our hospital[40].

\section{Immunohistochemistry}

Immunohistochemistry was performed on serial 4- $\mu \mathrm{m}$ tick paraffin slides. Table 2 presents all antibodies, dilutions, incubation times, and antigen-retrieval methods used. For all stainings, slides were deparaffinized with xylene and serial ethanol dilutions, and endogenous peroxidase activity was blocked in a buffer solution of $\mathrm{pH} 5.8$ with hydrogen peroxide followed by antigen retrieval. For HIF- $1 \alpha$, antigen retrieval was performed with EDTA buffer $\mathrm{pH} 9.0$ for 20 minutes at boiling temperature. After a cooling down period of 20 minutes, slides were incubated with a protein block (Vision Biosystems, Novocastra Laboratories Ltd, Newcastle Upon Tyne, United Kingdom) for 5 minutes, followed by anti-HIF-1 $\alpha$ antibody (mouse monoclonal, BD Transduction Laboratories, dilution 1:50, overnight $4^{\circ} \mathrm{C}$ ). Incubation with the secondary antibody (Post Primary block, Novocastra) for 30 minutes was preceded by incubation of Novolink ${ }^{\text {TM }}$ polymer (Novocastra) for 30 minutes. For $\mathrm{p} 27^{\mathrm{kip} 1}$ staining, antigen retrieval was performed with citrate buffer, $\mathrm{pH}$ 6.0, for 20 minutes at boiling temperature. After a cooling down period of 20 minutes the slides were incubated with the primary antibody (Kip1/p27, BD Transduction Laboratories; dilution 1:500, overnight $4^{\circ} \mathrm{C}$ ) followed by the secondary antibody (Powervision, ImmunoVision Technologies, Brisbane, CA, USA; ready to use, 30 minutes) as before[35]. For CAIX and Glut-1 staining protocols were used as before[6,7,23]. Slides were developed 
Table 2: Overview of the antibodies used and tissue processing details.

\begin{tabular}{|c|c|c|c|c|c|c|c|c|}
\hline Primary Anti Body & Type Anti Body & Source & Dilution & Antigen Retrieval & Second step & Positive control & Incubation time/temp (primary antibody) & Procedure \\
\hline HIF-1a & MoAb & $\begin{array}{l}\text { Transdu } \\
\text { ction }\end{array}$ & $1: 50$ & $\begin{array}{l}\text { EDTA, Ph9.0, } 20 \\
\text { minutes, } 93^{\circ} \mathrm{C}\end{array}$ & NV & mamma & $\mathrm{o} / \mathrm{n} 4^{\circ} \mathrm{C}$ & By hand \\
\hline Glut-1 & PoAb, Rabbit & DAKO & $1: 200$ & $\begin{array}{l}\text { Citrate, } \mathrm{Ph} 6.0,20 \\
\text { minutes, } 93^{\circ} \mathrm{C}\end{array}$ & $\begin{array}{l}\text { G-AR IgG + } \\
\text { strep } 1\end{array}$ & Placenta & 60 minutes/room temp & Autostainer \\
\hline CAIX & PoAb, Rabbit & Abcam & $1: 1000$ & $\begin{array}{l}\text { Citrate, } \mathrm{Ph} 6.0,20 \\
\text { minutes, } 93^{\circ} \mathrm{C}\end{array}$ & PV & Grawitz tumour & 60 minutes/room temp & By hand \\
\hline p27kip1 & MoAb & $\begin{array}{l}\text { Transdu } \\
\text { ction }\end{array}$ & $1: 500$ & $\begin{array}{l}\text { Citrate, } \mathrm{Ph} 6.0,20 \\
\text { minutes, } 93^{\circ} \mathrm{C}\end{array}$ & PV & Skin & $\mathrm{o} / \mathrm{n} 4^{\circ} \mathrm{C}$ & By hand \\
\hline
\end{tabular}

HIF-1a = hypoxia-inducible factor-1a; Glut-1 = glucose transporter-1; CAIX = carbonic anhydrase IX; MoAb = monoclonal antibody; PoAb = polyclonal antibody; Transduction = BD Transduction Laboratories, BD Biosciences, San Diego, CA, USA; DAKO = DAKOCytomation, Glostrup, Denmark; Abcam = Abcam, Cambridge Science Par, Cambridge, UK; G-aR IgG = biotinylated Goat-anti Rabbit IgG (BA-1000, Vector laboratories, CA, diluted 1:500) + strep 1 = Streptavidin peroxidase labelling (Streptavidin HRP IM0309, Beckman Coulter, diluted 1:100); NV = Novolink ${ }^{\text {TM }}$ polymer (Novocastra); $\mathrm{PV}=$ Powervision ready to use (Poly-HRP-anti Ms/Rb/RtlgG biotin free, ImmunoLogic, ImmunoVision technologies, Brisbane CA, USA). 
with diaminobenzidine for 10 minutes, followed by haematoxylin counterstaining. In between steps, slides were washed in PBS. Before the slides were mounted, all sections were dehydrated in alcohol and xylene. Appropriate positive and negative controls were used throughout.

\section{Evaluation of Staining}

Scoring was performed by two observers (PJvD, LS) as before$[6,7,23]$. Stainings were scored blinded to clinicopathologic data and results of other stainings. For HIF- $1 \alpha$ and p27kip1, the percentage of dark, homogenously stained nuclei was estimated, ignoring cytoplasmic staining. Both were considered positive when $\geq 1 \%$ staining was seen. Glut-1 and CAIX were considered positive when membrane staining was seen. The pattern of HIF$1 \alpha$, Glut-1 and CAIX was noted as purely diffuse (throughout the tumour without emphasis on areas with necrosis, thought to be due to non-hypoxic stimuli), perinecrotic (only positive staining around a necrotic area, thought to be hypoxia induced) or a combination of these two ("mixed"). No double staining was performed as this was done previously in breast cancer, and no further topographic analysis of staining was performed[7]. For $\mathrm{p} 27^{\mathrm{kip} 1}$, the pattern of staining was noted as perinecrotic, centrally in tumour islands (as these may be prenecrotic areas), diffuse or mixed.

\section{Statistical Analysis}

The Chi-square test or Fisher's Exact test (when appropriate) were used to evaluate correlations between HIF$1 \alpha$ expression, presence of necrosis, p27kip1 expression and stage, grade, myometrial invasion. Correlations between HIF-1 $\alpha$, CAIX and Glut-1 expression were evaluated with McNemar's test and Spearman rank correlation coefficient. Mann-Whitney-U was used to assess HIF- $1 \alpha$ expression and age at time of diagnosis. For univariate survival analysis, the HIF- $1 \alpha$ staining pattern or the $75 \%$ percentile (35\%) was chosen as cut-off value for HIF- $1 \alpha$ and $\mathrm{p}^{27^{\mathrm{kip}} 1}$ expression, closely corresponding to the proportion of patients that remained alive and well (81\%). Kaplan-Meier curves were plotted, and differences between the curves were analyzed with the log-rank test to test disease-free survival (DFS) and overall survival (OS). Cox proportional hazard was used for the multivariate survival analysis entering stage, grade, myometrial invasion, age, perinecrotic HIF- $1 \alpha$ and p27kip 1 expression as covariates. Two sided uncorrected p-values $<0.05$ were considered statistically significant. All analysis were performed with SPSS for Windows version 15.0; SPSS Inc., Chicago, IL, USA.

\section{Results}

\section{HIF-1 $a$ and necrosis}

Detectable levels of HIF-1 $\alpha$ were found in all endometrial carcinomas. The mean level of nuclear staining for HIF-
$1 \alpha$ was $26 \%$ (median, 20\%; range, $1-90 \%$ ). 20/93 cases (21\%) showed a purely perinecrotic staining pattern, 39/ $93(42 \%)$ a purely diffuse pattern, and 34/93 (37\%) showed a mixed (diffuse and perinecrotic) pattern (figure 1). Necrosis was found in $73 / 93$ (75\%) of the endometrial carcinomas. Not all tumours with necrosis showed perinecrotic HIF- $1 \alpha$ expression.

Presence of perinecrotic HIF-1 $\alpha$ expression was significantly associated with high-grade tumours (table 3 ). Nine out of 28 tumours (32\%) showed perinecrotic HIF-1 $\alpha$ expression in grade 1 tumours compared with $70 \%$ grade 2 and grade 3 tumours $\left(x^{2}\right.$-test, $\left.\mathrm{p}=0.004\right)$. HIF-1a expression in endometrioid endometrial cancer was not stage dependent and there was no association of perinecrotic HIF- $1 \alpha$ expression and depth of myometrial invasion or age. Similarly, necrosis was more often seen in high grade than in low grade tumours $\left(\chi^{2}\right.$-test, $\left.\mathrm{p}=0.003\right)$. No association was found between necrosis and tumour stage, depth of myometrial invasion or age.

\section{p27kip1 protein expression}

Expression of p27kip 1 was found in 86/93 (93\%) of endometrial carcinomas (figure 1). The mean level of nuclear staining for $\mathrm{p} 27^{\mathrm{kip} 1}$ was $24 \%$ (median, $20 \%$; range $0-100 \%$ ). There was no correlation between percentage $\mathrm{p} 27^{\mathrm{kip} 1}$ positive cells and stage, grade, age, HIF- $1 \alpha$ expression pattern or necrosis (additional file 1 ). In $56 \%$ of the tumours (30/54) with perinecrotic HIF-1 $\alpha$ expression, we observed central/perinecrotic p27kip1 staining (McNemar; $\mathrm{p}<0.0001)$. $\mathrm{p}^{\mathrm{kip} 1}$ staining pattern did not correlate with age, stage or myometrial invasion. However, perinecrotic/central p27kip1 expression pattern was correlated with higher grade $(\mathrm{p}=0.046)$.

\section{CAIX and Glut-1 expression in relation with HIF-1a}

CAIX was expressed in 71/93 (76\%) cases. Glut-1 showed membranous expression in 76/93 (81\%) cases. Positive expression of both CAIX and Glut- 1 was seen in $68 \%$ of the perinecrotic HIF- $1 \alpha$ expressing tumours compared to $32 \%$ of the diffuse group ( $\chi^{2}$-test, 0.007$)$. Perinecrotic HIF- $1 \alpha$ expression was also significantly associated with CAIX or Glut-1 expression (McNemar; $\mathrm{p}=0.004$ respectively $\mathrm{p}<0.0001)$. The 54 cases with any perinecrotic HIF$1 \alpha$ expression showed positive expression of CAIX or Glut-1 in 47/54 and 48/53 cases, respectively. Diffuse HIF- $1 \alpha$ expression was accompanied by CAIX expression in $24 / 39$ or Glut-1 expression in 28/39 cases. Levels of HIF-1 $\alpha$ expression correlated with expression levels of CAIX ( Spearman; $\mathrm{p}=0.012$ ) but not with expression levels of Glut-1.

\section{Survival analysis results}

Locoregional recurrences (vaginal, pelvic, or both) or distant metastases were found in 18 of 93 patients. Three patients with unknown recurrence status were censored 

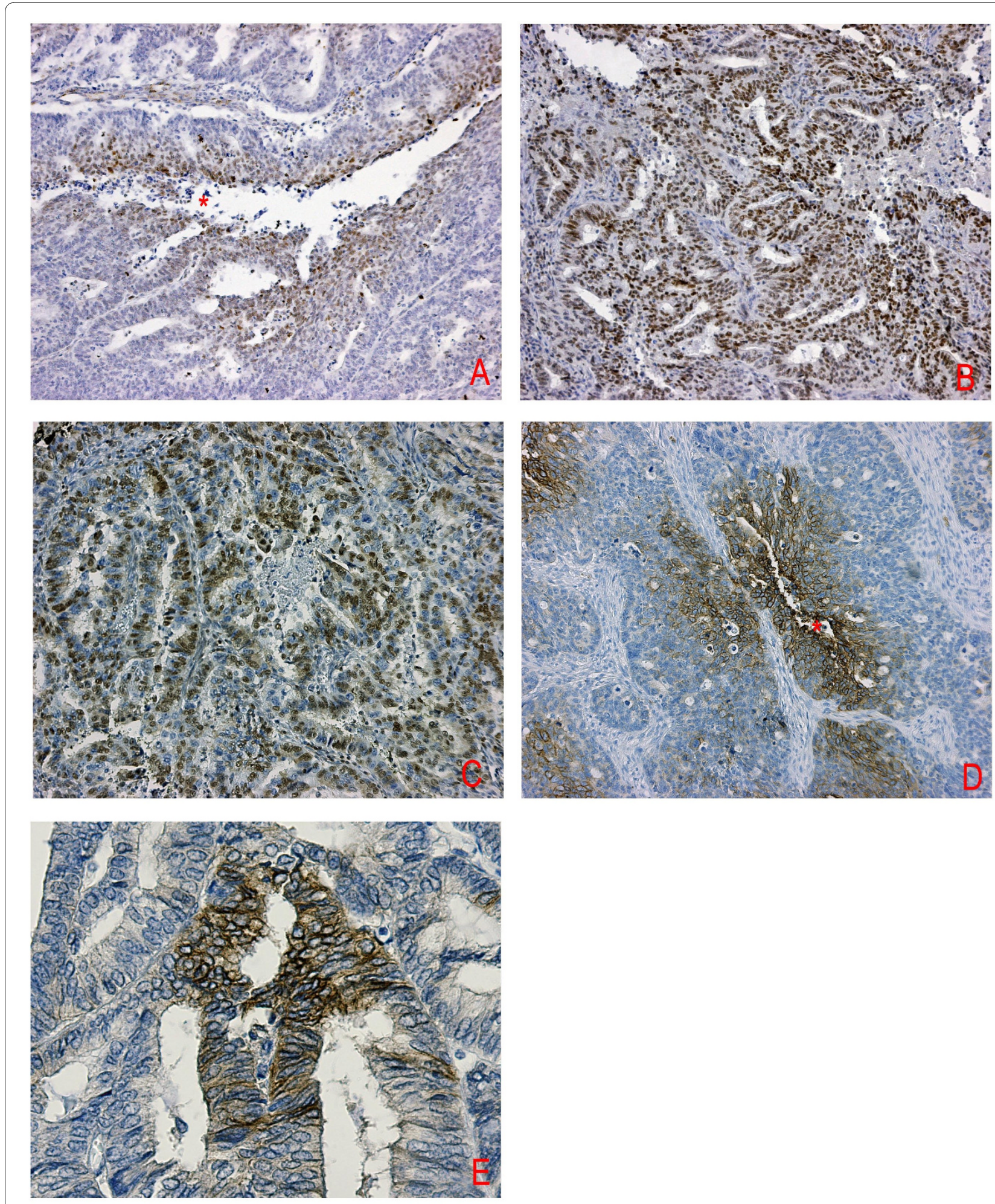

Figure 1 Immunohistochemical staining of HIF-1a, CAIX, Glut-1 and p27kip 1 in endometrioid endometrial carcinoma. Typical patterns are shown: A) perinecrotic HIF-1a expression (10x magnification). B) Diffuse HIF-1a expression (10x magnification). C) Diffuse p27kip1 expression (10X magnification). D) Perinecrotic Glut-1 expression (10x magnification) E) Membrane CAIX expression (20x magnification). Asterisk indicates necrosis. 
Table 3: Associations between HIF-1a staining pattern, clinicopathological features and expression of CAIX, Glut-1 and p27kip1.

\section{Perinecrotic HIF-1a}

\begin{tabular}{|c|c|c|c|c|}
\hline & & Yes (\%) & No (\%) & P-value \\
\hline \multirow[t]{4}{*}{ Stage } & 1 & $30(56)$ & $24(44)$ & \\
\hline & $\|$ & $12(57)$ & $9(43)$ & 0.845 \\
\hline & III & $9(69)$ & $4(31)$ & \\
\hline & IV & $3(60)$ & $2(40)$ & \\
\hline \multirow[t]{3}{*}{ Grade } & 1 & $9(32)$ & $19(68)$ & \\
\hline & 2 & $33(70)$ & $14(30)$ & 0.004 \\
\hline & 3 & $12(67)$ & $6(33)$ & \\
\hline \multirow[t]{3}{*}{ Myometrial Invasion } & 0 & 0 & $3(100)$ & \\
\hline & $<50 \%$ & $29(58)$ & $21(42)$ & 0.107 \\
\hline & $>50 \%$ & $25(63)$ & $15(37)$ & \\
\hline \multirow[t]{2}{*}{ Necrosis } & Yes & $54(77)$ & $16(23)$ & $<0.0001$ \\
\hline & No & 0 & $23(100)$ & \\
\hline \multirow[t]{2}{*}{ Recurrence/Metastasis } & Yes & $14(79)$ & $4(22)$ & 0.043 \\
\hline & No & $37(51)$ & $35(49)$ & \\
\hline \multirow[t]{2}{*}{ p27kip1 } & Pos & $48(89)$ & $38(97)$ & 0.125 \\
\hline & Neg & $6(11)$ & $1(3)$ & \\
\hline \multirow[t]{2}{*}{ p27kip1 } & $\leq 50 \%$ & $48(58)$ & $35(42)$ & 0.896 \\
\hline & $>50 \%$ & $6(60)$ & $4(40)$ & \\
\hline \multirow[t]{2}{*}{ p27kip1 expression pattern } & Peri/central & $30(91)$ & $3(9)$ & $<0.0$ \\
\hline & Other* & $24(40)$ & $36(60)$ & 001 \\
\hline \multirow[t]{2}{*}{ CAIX } & Pos & $47(67)$ & $24(33)$ & 0.004 \\
\hline & $\mathrm{Neg}$ & $7(32)$ & $15(68)$ & \\
\hline \multirow[t]{2}{*}{ Glut-1 } & Pos & $48(63)$ & $28(37)$ & 0.035 \\
\hline & $\mathrm{Neg}$ & $6(35)$ & $11(65)$ & \\
\hline \multirow[t]{2}{*}{ CAIX and Glut-1 } & Pos & $42(68)$ & $20(32)$ & 0.007 \\
\hline & $\mathrm{Neg}$ & $12(39)$ & $19(61)$ & \\
\hline
\end{tabular}

HIF-1a = hypoxia-inducible factor 1a; CAIX = carbonic anhydrase IX; Glut-1 = glucose transporter 1, * other staining patterns include diffuse staining or negative for p27kip1. 

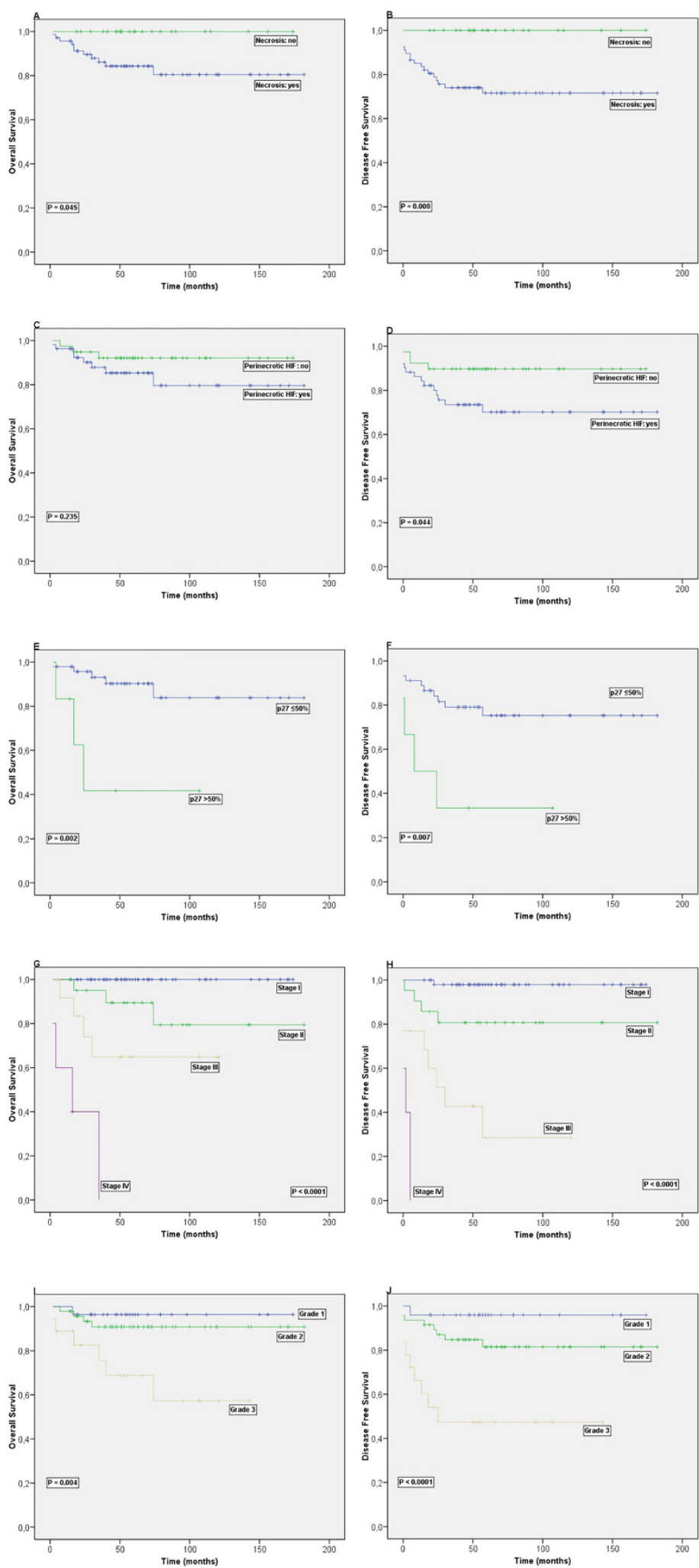

Figure 2 Kaplan-Meier survival curves illustrating disease-free survival and overall survival for endometrioid endometrial carcinoma patients $(\mathbf{n}=93)$ with tumour necrosis $(A, B)$ and patients with perinecrotic type HIF-1a expression $(C, D)$. $E$ and $F$ show the survival for the patients with perinecrotic HIF-1a expression $(n=51)$ and high $p 27$ kipl expression. Stage and grade show prognostic value as expected in $G$ - J. 
for disease free survival analysis. Stage and grade showed prognostic value as expected, underlining the representativeness of the patient group (see Figure 2). Univariate analysis (Kaplan-Meier, log rank test) for the whole group of patients showed that necrosis was correlated with shortened disease free survival (DFS) $(\mathrm{p}=0.008)$ and overall survival (OS) $(\mathrm{p}=0.045)$. For DFS, perinecrotic HIF- $1 \alpha$ expression also was prognostic $(\mathrm{p}=0.044)$, as shown in figure 2 . HIF expression in more than $35 \%$ of cells was associated with a shorter OS ( $p=0.032)$. CAIX expression was not correlated with survival. Membranous Glut-1 expression however correlated with a shorter DFS ( $\mathrm{p}=0.037)$. Subgroup analysis of low stage (stage I and II) $(n=75)$ patients did show perinecrotic HIF- $1 \alpha$ expression also to be an indicator of shorter disease free survival in this patient group $(\mathrm{p}=0.033)$, while significance was lost in the stage III/IV $(\mathrm{n}=18)$ subgroups $(\mathrm{p}=$ 0.737).

P27kip1 expression or expression pattern had no significant relation to prognosis. Subgroup analysis of patients with perinecrotic HIF- $1 \alpha$ expression $(n=55)$ revealed that high $\mathrm{p} 27^{\mathrm{kip} 1}$ expression ( $>50 \%$ positive cells) was an additional prognostic factor indicating a poor prognosis for DFS ( $p=0.007)$ and OS ( $p=0.002)$ in this subgroup.

In a multivariate model together with stage, grade, depth of myometrial invasion and age at diagnosis, only perinecrotic HIF- $1 \alpha$ expression emerged as an additional prognostic factor to stage and age for DFS ( $p=0.044$; RR: 0.312; 95\% Confidence Interval 0.100-0.972). Multivariate analysis of patients with perinecrotic HIF- $1 \alpha$ expression, showed high $\mathrm{p} 27^{\mathrm{kip} 1}$ to be a prognostic factor for DFS above stage and age ( $\mathrm{p}=0.011$; RR: 6.735 95\% Confidence Interval 1.557-29.122).

\section{Discussion}

Hypoxia and its key regulator HIF-1 $\alpha$ have been shown to play an important role in endometrial carcinogenesis [23], but contradictory results have been published as to the prognostic value of HIF- $1 \alpha$ overexpression in endometrial carcinoma[27-30], while expression patterns have been ignored. The aim of this study was therefore to reevaluate the prognostic value of HIF-1 $\alpha$ overexpression in a representative group of patients with endometrioid endometrial cancer, with emphasis on expression patterns. Also, as p $27^{\mathrm{kip} 1}$ is re-expressed in hypoxic regions of EEC [35], we investigated the additional effect of p27kip1 expression on predicting survival in EEC. HIF-1 $\alpha$ overexpression, especially the perinecrotic type, and necrosis appeared to be independent indicators of poor prognosis. High p27kip1 ( $>50 \%$ positive cells) expression was an additional prognostic factor in the subgroup of patients with perinecrotic type of HIF- $1 \alpha$ expression.

Our results on the prognostic value of HIF- $1 \alpha$ overexpression are in line with those of Sivridis et al.[27] where
HIF-1 $\alpha$ was associated with a shorter overall survival in stage 1 endometrial cancer. However, others did not find a significant prognostic impact of HIF-1 $\alpha$ overexpression[28-30]. Immunohistochemical HIF-1 $\alpha$ studies are difficult to compare because of a variation in the definition of HIF- $1 \alpha$ positivity. Previous studies did not consider the different expression patterns throughout the tumours (diffuse versus perinecrotic) that have been shown in other cancers to be prognostically crucial[7]. Another difference between the present and previous studies is the cut off value for HIF- $1 \alpha$ expression. In the present study, the cut off value for prognostic value of HIF- $1 \alpha$ was $35 \%$, much higher than in other studies where the cut off varied between $1 \%$ and $5 \%[6,41]$. Our results indicate that also in endometrial cancer, the pattern of HIF- $1 \alpha$ expression is more important for the prognosis than percentage and intensity of HIF- $1 \alpha$ expressing cells in general. This significance of expression pattern could be explained by the fact that perinecrotic HIF-1 $\alpha$ expression is thought to be hypoxia driven, whereas diffuse HIF- $1 \alpha$ expression may rather be due to non-hypoxic stimuli[6,7]. In a previous study from our group[23] we showed that diffuse HIF-1 $\alpha$ expression was associated with the highest microvessel density (MVD); perinecrotic and mixed patterns were associated with an intermediate MVD ( $\mathrm{p}<0.05)$. This indicates that diffuse HIF- $1 \alpha$ expression is more likely to be due to nonhypoxic stimuli than to non-necrosis associated hypoxia. We showed that perinecrotic HIF- $1 \alpha$ expression is more often accompanied by activation of its downstream factors Glut-1 and CAIX, indicating it to be more active than diffuse HIF-1 $\alpha$. More activation of HIF- $1 \alpha$ and its target genes would give more tumour cells a survival advantage in a hypoxic environment. Perinecrotic HIF-1 $\alpha$ expression retained its prognostic significance in the subgroup of low stage, while significance was lost in stage III/IV patients, indicating that HIF- $1 \alpha$ expression seems to be especially important in low stage patients. However, sample size of the subgroups (especially the high stages) was limiting. Therefore, no definitive conclusions on the prognostic value of HIF- $1 \alpha$ in high stage patients can be made. Loss of $\mathrm{p} 27^{\mathrm{kip} 1}$ expression has been reported for a number of human tumour types and has been correlated with poor prognosis and tumour aggressiveness[36,42]. Only one study showed a correlation between p27kip1 expression and prognosis in endometrial cancer[43]. However, we found no prognostic influence of global p27kip1 expression in endometrioid endometrial carcinoma. This is in line with the outcome of others $[38,39,44]$. Since we found hypoxia to be able to induce re-expression of $\mathrm{p} 27^{\mathrm{kip} 1}$ in a HIF-1 $\alpha$ dependent way in a previous study[35], we evaluated the prognostic value of p27kip1 in relation to HIF- $1 \alpha$ in the present study. In the subgroup of patients with perinecrotic HIF-1 $\alpha$ expres- 
sion, high p27kip1 expression ( $>50 \%$ positive cells) was associated with a shorter DFS and OS. This fits with our previously proposed model that hypoxia induced reexpression of $\mathrm{p} 27^{\mathrm{kip} 1}$ may result in dormancy of hypoxic cells, which in combination with HIF- $1 \alpha$ induced expression of genes regulating supply of energy, growth factors and other survival factors, may promote cellular survival and adaptation of sub clones within the tumour that may contribute to metastatic disease and poor clinical outcome. In our previous study however, only central/ perinecrotic $\mathrm{p} 27_{\mathrm{kip} 1}$ expression was associated with HIF$1 \alpha$ induced re-expression[35]. In the present study, central/perinecrotic p27kip1 expression was still associated with perinecrotic HIF-1 $\alpha$ expression; however this subgroup was too small to correlate with survival data.

Interestingly, all patients lacking tumour necrosis survived, and none of these patients developed a locoregional or distant recurrence. The prognostic value of necrosis is in concordance with previous results by Scholten et al.[45] who showed that necrosis is a significant prognostic factor in Stage I-III endometrioid endometrial carcinoma. Although necrosis is a strong independent prognostic factor for endometrial carcinoma, its clinical use may be limited because of a moderate reproducibility[45-47]. Further, excluding the presence of necrosis requires adequate sampling. More objective biomarkers like perinecrotic HIF-1 $\alpha$ expression could result in a higher reproducibility.

\section{Conclusions}

We conclude that in endometrioid endometrial carcinoma, absence of necrosis is a favourable prognostic factor. Tumours with a perinecrotic HIF-1 expression are more aggressive than tumours with purely diffuse HIF-1 expression. Furthermore, the combination of perinecrotic HIF expression and high p27kip1 expression is indicative for an unfavourable prognosis. More aggressive adjuvant treatment might be necessary to improve the outcome of these patients. To this end, targeting the HIF pathway might provide an attractive strategy to treat hypoxic and highly angiogenic tumours. Thus far, selective HIF-1 inhibitors have not been identified. A number of nonselective inhibitors, which indirectly target signaling pathways upstream or downstream of HIF-1 are known to decrease the key regulating HIF-1 $\alpha$ protein levels. Preliminary results show encouraging results for these single agent treatments, however severe toxicities have been encountered. Lack of specificity increases the difficulty in attributing any anti-tumorigenic effects of these drugs specifically to inhibition of HIF-1. Further studies are needed to show whether adaptation of therapy protocols might be of benefit for endometrial cancer patients with perinecrotic HIF-1 $\alpha$ overexpression.

\section{Additional material}

Additional file 1 Associations between $\mathrm{p} 27^{\mathrm{kip} 1}$ staining pattern, clinicopathological features, necrosis and HIF-1 a expression pattern

\section{Competing interests}

The authors declare that they have no competing interests.

\section{Authors' contributions}

LS and NH contributed equally to the manuscript. LS collected samples, performed immunohistochemistry, analysed data, carried out data interpretation and drafted the manuscript. $\mathrm{NH}$ participated in the conception and design of the study, collected samples, performed immunohistochemistry, and drafted the manuscript. PG provided technical support and performed immunohistochemistry. EW and RV participated in design of the study and critically revised the manuscript. PD participated in the conception and design of the study, performed revision and new histological staging of samples, supervised statistics and critically revised the manuscript. All authors read and approved the final manuscript.

Acknowledgements

This work was supported by the Dutch Cancer Society project 2009-4375.

\section{Author Details}

1Department of Gynaecological Oncology, University Medical Centre Utrecht Utrecht, The Netherlands, 2Department of Pathology, University Medical Centre Utrecht, Utrecht, The Netherlands and ${ }^{3}$ Department of Internal Medicine, University Medical Centre Utrecht, Utrecht, The Netherlands

Received: 26 November 2009 Accepted: 19 June 2010

Published: 19 June 2010

\section{References}

1. Jemal A, Siegel R, Ward E, Hao Y, Xu J, Thun MJ: Cancer statistics, 2009. CA Cancer J Clin 2009, 59:225-249.

2. Creasman WT, Odicino F, Maisonneuve P, Quinn MA, Beller U, Benedet JL, Heintz AP, Ngan HY, Pecorelli S: Carcinoma of the corpus uteri. FIGO 6th Annual Report on the Results of Treatment in Gynecological Cancer. Int J Gynaecol Obstet 2006, 95(Suppl 1):S105-S143.

3. Shimizu S, Eguchi Y, Kamiike W, Itoh Y, Hasegawa J, Yamabe K, Otsuki Y, Matsuda $H$, Tsujimoto $Y$ : Induction of apoptosis as well as necrosis by hypoxia and predominant prevention of apoptosis by $\mathrm{Bcl}-2$ and $\mathrm{BCl}-\mathrm{XL}$. Cancer Res 1996, 56:2161-2166.

4. Kurokawa T, Miyamoto M, Kato K, Cho Y, Kawarada Y, Hida Y, Shinohara T, Itoh T, Okushiba S, Kondo S, et al:: Overexpression of hypoxia-induciblefactor 1alpha(HIF-1alpha) in oesophageal squamous cell carcinoma correlates with lymph node metastasis and pathologic stage. $\mathrm{Br} J$ Cancer 2003, 89:1042-1047.

5. Le QT, Denko NC, Giaccia AJ: Hypoxic gene expression and metastasis. Cancer Metastasis Rev 2004, 23:293-310.

6. Bos R, van der Groep P, Greijer AE, Shvarts A, Meijer S, Pinedo HM, Semenza GL, van Diest PJ, van der Wall E: Levels of hypoxia-inducible factor-1alpha independently predict prognosis in patients with lymph node negative breast carcinoma. Cancer 2003, 97:1573-1581.

7. Vleugel MM, Greijer AE, Shvarts A, van der Groep P, van Berkel M, Aarbodem $\mathrm{Y}$, van Tinteren $\mathrm{H}$, Harris AL, van Diest PJ, van der Wall E: Differential prognostic impact of hypoxia induced and diffuse HIF1 alpha expression in invasive breast cancer. J Clin Pathol 2005, 58:172-177

8. Schindl M, Schoppmann SF, Samonigg H, Hausmaninger H, Kwasny W Gnant M, Jakesz R, Kubista E, Birner P, Oberhuber G: Overexpression of hypoxia-inducible factor 1 alpha is associated with an unfavorable prognosis in lymph node-positive breast cancer. Clin Cancer Res 2002, 8:1831-1837.

9. Harrison L, Blackwell K: Hypoxia and anemia: factors in decreased sensitivity to radiation therapy and chemotherapy? Oncologist 2004, 9(Suppl 5):31-40

10. Unruh A, Ressel A, Mohamed HG, Johnson RS, Nadrowitz R, Richter E, Katschinski DM, Wenger RH: The hypoxia-inducible factor-1 alpha is a negative factor for tumor therapy. Oncogene 2003, 22:3213-3220. 
11. Greijer AE, de Jong MC, Scheffer GL, Shvarts A, van Diest PJ, van der Wall E: Hypoxia-induced acidification causes mitoxantrone resistance not mediated by drug transporters in human breast cancer cells. Cell Oncol 2005, 27:43-49.

12. Jiang BH, Semenza GL, Bauer C, Marti HH: Hypoxia-inducible factor 1 levels vary exponentially over a physiologically relevant range of $\mathrm{O} 2$ tension. Am J Physiol 1996, 271:C1172-C1180.

13. Greijer AE, van der Groep $P$, Kemming D, Shvarts A, Semenza GL, Meijer $G A$, van de Wiel MA, Belien JA, van Diest PJ, van der Wall E: Up-regulation of gene expression by hypoxia is mediated predominantly by hypoxiainducible factor 1 (HIF-1). J Pathol 2005, 206:291-304.

14. Huang LE, Arany Z, Livingston DM, Bunn HF: Activation of hypoxiainducible transcription factor depends primarily upon redox-sensitive stabilization of its alpha subunit. J Bio/ Chem 1996, 271:32253-32259.

15. Semenza GL: Regulation of mammalian $\mathrm{O} 2$ homeostasis by hypoxiainducible factor 1. Annu Rev Cell Dev Biol 1999, 15:551-578.

16. Semenza GL: HIF-1: mediator of physiological and pathophysiological responses to hypoxia. J App/ Physiol 2000, 88:1474-1480.

17. Ratcliffe PJ, O'Rourke JF, Maxwell PH, Pugh CW: Oxygen sensing, hypoxiainducible factor-1 and the regulation of mammalian gene expression. J Exp Biol 1998, 201:1153-1162.

18. Vaughan-Jones RD, Spitzer KW: Role of bicarbonate in the regulation of intracellular $\mathrm{pH}$ in the mammalian ventricular myocyte. Biochem Cell Biol 2002, 80:579-596.

19. Behrooz A, Ismail-Beigi F: Stimulation of Glucose Transport by Hypoxia: Signals and Mechanisms. News Physio/ Sci 1999, 14:105-110.

20. Pedersen MW, Holm S, Lund EL, Hojgaard L, Kristjansen PE: Coregulation of glucose uptake and vascular endothelial growth factor (VEGF) in two small-cell lung cancer (SCLC) sublines in vivo and in vitro. Neoplasia 2001, 3:80-87.

21. Giatromanolaki A, Koukourakis MI, Sivridis E, Pastorek J, Wykoff CC, Gatter KC, Harris AL: Expression of hypoxia-inducible carbonic anhydrase- 9 relates to angiogenic pathways and independently to poor outcome in non-small cell lung cancer. Cancer Res 2001, 61:7992-7998.

22. Loncaster JA, Harris AL, Davidson SE, Logue JP, Hunter RD, Wycoff CC, Pastorek J, Ratcliffe PJ, Stratford IJ, West CM: Carbonic anhydrase (CA IX) expression, a potential new intrinsic marker of hypoxia: correlations with tumor oxygen measurements and prognosis in locally advanced carcinoma of the cervix. Cancer Res 2001, 61:6394-6399.

23. Horree N, van Diest PJ, van der Groep P, Sie-Go DM, Heintz AP: Hypoxia and angiogenesis in endometrioid endometrial carcinogenesis. Cell Oncol 2007, 29:219-227.

24. Birner P, Gatterbauer B, Oberhuber G, Schindl M, Rossler K, Prodinger A, Budka H, Hainfellner JA: Expression of hypoxia-inducible factor-1 alpha in oligodendrogliomas: its impact on prognosis and on neoangiogenesis. Cancer 2001, 92:165-171.

25. Birner P, Schindl M, Obermair A, Plank C, Breitenecker G, Oberhuber G: Overexpression of hypoxia-inducible factor 1alpha is a marker for an unfavorable prognosis in early-stage invasive cervical cancer. Cancer Res 2000, 60:4693-4696.

26. Osada R, Horiuchi A, Kikuchi N, Yoshida J, Hayashi A, Ota M, Katsuyama Y, Mellilo G, Konishi I: Expression of hypoxia-inducible factor 1alpha, hypoxia-inducible factor 2alpha, and von Hippel-Lindau protein in epithelial ovarian neoplasms and allelic loss of von Hippel-Lindau gene: nuclear expression of hypoxia-inducible factor 1alpha is an independent prognostic factor in ovarian carcinoma. Hum Patho/ 2007, 38:1310-1320

27. Sivridis E, Giatromanolaki A, Gatter KC, Harris AL, Koukourakis MI: Association of hypoxia-inducible factors 1 alpha and 2alpha with activated angiogenic pathways and prognosis in patients with endometrial carcinoma. Cancer 2002, 95:1055-1063.

28. Acs G, Xu X, Chu C, Acs P, Verma A: Prognostic significance of erythropoietin expression in human endometrial carcinoma. Cancer 2004, 100:2376-2386.

29. Pansare V, Munkarah AR, Schimp V, Haitham AM, Saed GM, Morris RT, IiFehmi R: Increased expression of hypoxia-inducible factor 1alpha in type I and type II endometrial carcinomas. Mod Pathol 2007, 20:35-43.

30. Pijnenborg JM, Wijnakker M, Hagelstein J, Delvoux B, Groothuis PG: Hypoxia contributes to development of recurrent endometrial carcinoma. Int J Gynecol Cancer 2007, 17:897-904.

31. Green SL, Giaccia AJ: Tumor hypoxia and the cell cycle: implications for malignant progression and response to therapy. Cancer J Sci Am 1998, 4:218-223.
32. Sherr CJ: The Pezcoller lecture: cancer cell cycles revisited. Cancer Res 2000, 60:3689-3695.

33. Bamberger AM, Riethdorf $L$, Milde-Langosch $K$, Bamberger CM, Thuneke I, Erdmann I, Schulte HM, Loning T: Strongly reduced expression of the cell cycle inhibitor p27 in endometrial neoplasia. Virchows Arch 1999, 434:423-428.

34. Schmitz MJ, Hendricks DT, Farley J, Taylor RR, Geradts J, Rose GS, Birrer MJ: p27 and cyclin D1 abnormalities in uterine papillary serous carcinoma. Gynecol Oncol 2000, 77:439-445.

35. Horree N, Gort E, van der Groep P, Heintz A, Vooijs M, van Diest P: Hypoxia-inducible factor 1 alpha is essential for hypoxic p27 induction in endometrioid endometrial carcinoma. J Pathol 2008, 214:38-45.

36. Catzavelos C, Bhattacharya N, Ung YC, Wilson JA, Roncari L, Sandhu C, Shaw P, Yeger H, Morava-Protzner I, Kapusta L, et al:: Decreased levels of the cell-cycle inhibitor p27Kip1 protein: prognostic implications in primary breast cancer. Nat Med 1997, 3:227-230.

37. Masciullo V, Sgambato A, Pacilio C, Pucci B, Ferrandina G, Palazzo J, Carbone A, Cittadini A, Mancuso S, Scambia G, et al.: Frequent loss of expression of the cyclin-dependent kinase inhibitor p27 in epithelial ovarian cancer. Cancer Res 1999, 59:3790-3794.

38. Masciullo V, Susini T, Zamparelli A, Bovicelli A, Minimo C, Massi D, Taddei G, Maggiano N, De IP, Ceccaroni M, et al:: Frequent loss of expression of the cyclin-dependent kinase inhibitor p27(Kip1) in estrogen-related Endometrial adenocarcinomas. Clin Cancer Res 2003, 9:5332-5338.

39. Erkanli S, Kayaselcuk F, Kuscu E, Bagis T, Bolat F, Haberal A, Demirhan B: Expression of survivin, PTEN and p27 in normal, hyperplastic, and carcinomatous endometrium. Int J Gynecol Cancer 2006, 16:1412-1418.

40. van Diest PJ: No consent should be needed for using leftover body material for scientific purposes. For. BMJ 2002, 325:648-651.

41. Beasley NJ, Leek R, Alam M, Turley H, Cox GJ, Gatter K, Millard P, Fuggle S, Harris AL: Hypoxia-inducible factors HIF-1alpha and HIF-2alpha in head and neck cancer: relationship to tumor biology and treatment outcome in surgically resected patients. Cancer Res 2002, 62:2493-2497.

42. Huang LW, Chao SL, Hwang JL, Chou YY: Down-regulation of p27 is associated with malignant transformation and aggressive phenotype of cervical neoplasms. Gynecol Oncol 2002, 85:524-528.

43. Watanabe J, Sato H, Kanai T, Kamata Y, Jobo T, Hata H, Fujisawa T, Ohno E, Kameya T, Kuramoto H: Paradoxical expression of cell cycle inhibitor p27 in endometrioid adenocarcinoma of the uterine corpus correlation with proliferation and clinicopathological parameters. $\mathrm{Br}$ J Cancer 2002, 87:81-85.

44. Nycum LR, Smith LM, Farley JH, Kost ER, Method MW, Birrer MJ: The role of p27 in endometrial carcinoma. Gynecol Oncol 2001, 81:242-246.

45. Scholten AN, Smit VT, Beerman H, van Putten WL, Creutzberg CL: Prognostic significance and interobserver variability of histologic grading systems for endometrial carcinoma. Cancer 2004, 100:764-772.

46. Lax SF, Kurman RJ, Pizer ES, Wu L, Ronnett BM: A binary architectural grading system for uterine endometrial endometrioid carcinoma has superior reproducibility compared with FIGO grading and identifies subsets of advance-stage tumors with favorable and unfavorable prognosis. Am J Surg Pathol 2000, 24:1201-1208.

47. Sagae S, Saito T, Satoh M, Ikeda T, Kimura S, Mori M, Sato N, Kudo R: The reproducibility of a binary tumor grading system for uterine endometrial endometrioid carcinoma, compared with FIGO system and nuclear grading. Oncology 2004, 67:344-350.

\section{Pre-publication history}

The pre-publication history for this paper can be accessed here: http://www.biomedcentral.com/1471-2407/10/307/prepub

\section{doi: 10.1186/1471-2407-10-307}

Cite this article as: Seeber et al., Necrosis related HIF-1? expression predicts prognosis in patients with endometrioid endometrial carcinoma BMC Cancer 2010, 10:307 